\title{
Nationwide Trends of Hospital Admission for Morbid Obesity in the USA
}

\author{
Rutaba Tajammal, Sultan Mahmood* and Salman Nusrat \\ University of Oklahoma Health Sciences Center, USA
}

Received: April 06, 2018; Published: April 16, 2018

*Corresponding author: Sultan Mahmood, University of Oklahoma Health Sciences Center, Oklahoma City, Oklahoma, OK 73114, USA, Tel: 4052718000; Fax: 8884111630; Email: Sultan-Mahmood@ouhsc.edu

\begin{abstract}
Obesity is a chronic disease that is increasing in prevalence and is now widely considered a global epidemic. The aim of this study was to evaluate the burden of inpatient admission, length of stay and associated cost related to inpatient management and how it has changed over the past two decades. Using data from the Nationwide Inpatient Sample and National Emergency Department Sample we examined the characteristics of hospitalization for Morbid Obesity (ICD-9 code 278.01) and evaluated the time trends of resource utilization from 1997 to 2012. Between 1997 and 2012, the number of hospitalizations with a discharge di

agnosis of morbid obesity increased from 2,224 to 5,634 (RR 2.3, p <0.001). The number of hospitalized patients older than 44 increased from $32.4 \%$ to $50.7 \%$ (RR 1.31, $\mathrm{p}=<0.001$ ). Aggregate charges increased 22 folds from $\$ 40,773,971$ to $\$ 891,215,569$. Our analysis shows that there has been an increasing burden of morbid obesity in the hospitalized population which corresponds with the increasing prevalence of obesity in the US during this same time period. There is also an increasing prevalence of morbid obesity in older population who tend to have longer hospital stays, and increased inpatient morbidity and mortality.
\end{abstract}

\section{Editorial}

Increased prevalence of obesity is a worldwide health concern and is now widely considered a global epidemic [1]. As the obesity epidemic worsens, societies are burdened by premature mortality, morbidity associated with many chronic conditions, and the negative impact on health-related quality of life [2]. Increase in BMI not only increases the risk of diabetes, atherosclerotic vascular disease and hypertension but has also been associated with increased incidence of various types of cancer [3]. The biggest challenge remains to adequately quantify the health burden of increasing obesity to inform public policies and health services. Some studies have shown that medical costs in obese individuals are generally $30 \%$ higher than those with normal weight. With the combination of rising obesity prevalence and increased spending on obese people, total health care costs attributable to obesity are expected to double every decade [4]. The aim of our study was to evaluate the burden of morbid obesity for inpatient admission, length of stay and associated cost related to inpatient management and how it has changed over the past two decades.

Using data from the Nationwide Inpatient Sample and National Emergency Department Sample we examined the characteristics of hospitalization for Morbid Obesity (ICD-9 code 278.01) and evaluated the time trends of resource utilization from 1997 to 2012. Fisher's exact test and two-sample t-test were used where appropriate. In 2012, the number of patients with a diagnosis of morbid obesity on discharge from the hospital was 5,634. Majority of these patients were females (77.4\%) and aged between 18 and 44 years $(52.8 \%)$. The mean charges per hospitalization were $\$ 2,359$ and resulted in a national bill of $\$ 99,791,407$. Based on regions defined by bureau of census, Southern States accounted for majority (69.6\%) of these hospitalizations. Only $9.2 \%$ patients were uninsured and median income for zip code was not low ( $>25$ percentile) for majority of the hospitalizations (78.5\%). Between 1997 and 2012, the number of hospitalizations with a discharge diagnosis of morbid obesity increased from 2,224 to 5,634 (relative risk 2.3 , 95\% CI: 2.1-2.4, p <0.001).

The number of hospitalized patients older than 44 years increased from $32.4 \%$ to $50.7 \%$ (relative risk 1.31 , 95\% CI: 1.23 $1.41, \mathrm{p}=<0.001$ ) despite a significant reduction in average length of stay from 2.52 to 0.28 days $(\mathrm{p}<0.001)$, aggregate charges increased 22 folds from $\$ 40,773,971$ to $\$ 891,215,569$ (\$ 627,336,951 when adjusted for inflation according to the Consumer Price Index). As expected, our analysis shows that there has been an increasing burden of morbid obesity in the hospitalized population. This 
corresponds with the increasing prevalence of obesity in the US during this same time period. There are gender and regional differences with females and southern states accounting for majority of admissions. There is also an increasing prevalence of morbid obesity in older population who tend to have longer hospital stays, and increased inpatient morbidity and mortality. From 1997 to 2012 , the number of hospitalizations and associated cost has also increased profoundly. Better understanding the scale of the problem can create increased awareness of the need for action and guide the policy makers to mobilize resources to this ever growing problem. Hopefully in the future obesity prevention programs will be successful in reversing this dangerous trend and we would see a decline in the inpatient burden of morbid obesity.

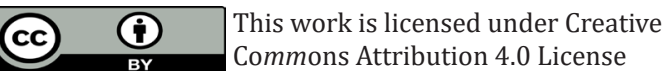

Submission Link: https://biomedres.us/submit-manuscript.php

\section{References}

1. Finucane MM, Stevens GA, Cowan MJ, Danaei G, Lin JK, et al. (2011) National, regional, and global trends in body-mass index since 1980: systematic analysis of health examination surveys and epidemiological studies with 960 country-years and 9.1 million participants. The Lancet 377(9765): 557-567.

2. Wang YC, Mc Pherson K, Marsh T, Gortmaker SL, Brown M (2011) Health and economic burden of the projected obesity trends in the USA and the UK. The Lancet 378(9793): 815-825.

3. Renehan AG, Tyson M, Egger M, Heller RF, Zwahlen M (2008) Body-mass index and incidence of cancer: a systematic review and meta-analysis of prospective observational studies. The Lancet 371(9612): 569-578.

4. Thorpe KE, Florence CS, Howard DH, Joski P (2004) The impact of obesity on rising medical spending. Health Affairs 23: W4 480-486.

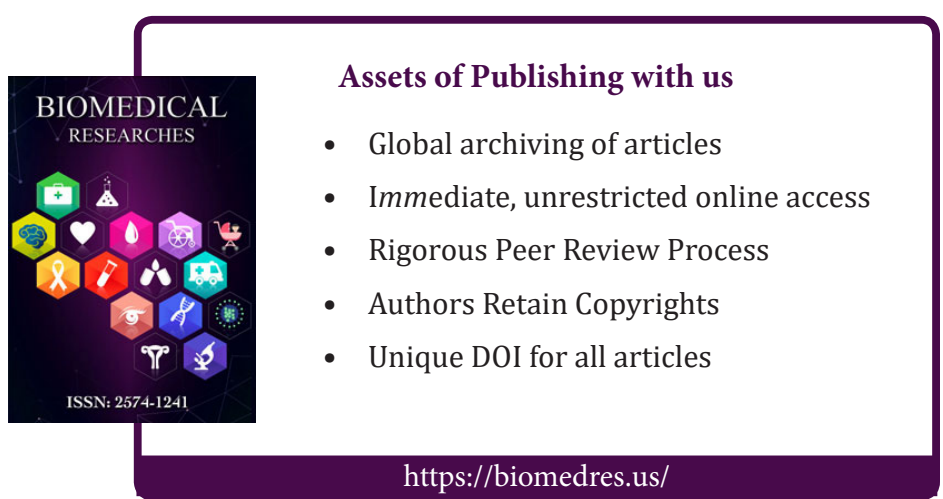

